\title{
INFLUENCE OF THE FABRICATION PROCESS OF COPPER MATRIX COMPOSITES ON CAVITATION EROSION RESISTANCE
}

\author{
Jovana Ružićl ${ }^{1 *}$, Jelena Stašić ${ }^{1}$, Dušan Božićl, Marina Dojčinović ${ }^{2}$, \\ Tatjana Volkov-Husovic ${ }^{2}$ \\ ${ }^{1}$ University of Belgrade, Vinča Institute of Nuclear Sciences, \\ Department of Materials Science, Belgrade, Serbia \\ ${ }^{2}$ University of Belgrade, Faculty of Technology and Metallurgy, \\ Belgrade, Serbia
}

Received 25.04.2017

Accepted 07.11.2017

\begin{abstract}
Copper matrix composites reinforced with $\mathrm{ZrB}_{2}$ particles were produced in two ways: by hot pressing (HP) and laser-sintering process. Powder mixture $\mathrm{Cu}-\mathrm{Zr}-\mathrm{B}$ was mechanically alloyed before densification processes. Variations in the microstructure of treated samples obtained during cavitation test were analyzed by scanning electron microscopy (SEM). Cavitation erosion resistance was investigated with the standard test method for cavitation erosion using vibratory apparatus. Changes in mechanical alloying duration show a strong influence on cavitation erosion resistance of $\mathrm{Cu}-\mathrm{ZrB}_{2}$ composites regardless the number of reinforcements. Laser-sintered samples show better cavitation erosion resistance than hot-pressed samples.

Keywords: copper-matrix composites; mechanical alloying; hot-pressing; lasersintering; cavitation erosion; scanning electron microscopy (SEM).

\section{Introduction}

In past decades, considerable attention was paid to the production of composite materials with the best combination of mechanical and physical properties. The copperbased composites are being examined as potential candidate materials in aerospace, automotive, military and electrical industry [1-3]. Low content of alloying elements in the copper matrix enables the highest possible ratio of mechanical/physical properties sufficient to withstand demanding operating conditions even in nuclear technology and rocket industry [4, 5]. Previous studies [6-8] showed that addition of $\mathrm{ZrB}_{2}$ as a hardening phase into the copper matrix significantly improved its mechanical properties, with maintaining high electrical and thermal conductivity. Combining mechanical alloying (MA) with hot pressing process enables proper distribution and in situ formation of $\mathrm{ZrB}_{2}$
\end{abstract}

\footnotetext{
*Corresponding author: Jovana Ružić, jruzic@vinca.rs
} 
particles in the copper matrix. This method shows excellent influence on mechanical and tribological properties since strong interfacial bonding between the coarse $\mathrm{ZrB}_{2}$ particles and $\mathrm{Cu}$-matrix is avoided [3-5]. On the other hand, by using laser-sintering, high super saturation occurs providing better formation of finer $\mathrm{ZrB}_{2}$ reinforcing particles in the copper matrix. During MA particles of $\mathrm{Zr}$ and B are mechanically activated which enables in situ formation of $\mathrm{ZrB}_{2}$ in a copper matrix in the course of hot pressing process or lasersintering [6]. All these facts enable excellent mechanical properties of the $\mathrm{Cu}-\mathrm{ZrB}_{2}$ composite. The occurrence of cavitation erosion is widespread in many engineering materials. This fact justifies an investigation of this kind of erosion of $\mathrm{Cu}-\mathrm{ZrB}_{2}$ composite.

The phenomenon of cavitation involves the formation, growth, and collapse of bubbles in a liquid due to the local pressure changes. When the pressure in liquid drops below the vapor pressure at a given temperature, microscopic bubbles are formed [9]. These bubbles can collapse suddenly if the liquid is subsequently subjected to a higher hydrostatic pressure. Collapsing bubbles produce shock waves and microjets which can cause high temperatures $\left(5000^{\circ} \mathrm{C}\right)$ and pressures $(103 \mathrm{MPa})$ on the surfaces of small dimensions $\left(10^{-10} \mathrm{~m}^{2}\right)$ in a short period $(<1 \mu \mathrm{s})[10,11]$. If these collapses repeated close to the solid surface, it is subjected to fatigue which can cause cavitation erosion. Material response to cavitation erosion is usually described as mass loss versus exposure time, and ideally the plotted data form the S-shaped curve. Formation of S-curve consists of several stages: incubation period, accelerating rate period, constant rate period, followed by oscillating rate periods and, in some cases, a final lower constant rate period [12]. In practice, the shape of this curve depends on material properties and its response to cavitation attack, i.e., cavitation resistance.

Several research studies have been devoted to understanding the phenomenon of cavitation erosion of conventional materials, which are used in the production of hydraulic machinery and other mechanical parts. They proved that the cavitation erosion resistance depends on mechanical parameters (hardness, tensile strength, Young's modulus, fatigue strength), microstructure (grain size, some material defects, present phases), and also on surface roughness [13-16]. Hence, many studies investigated the cavitation erosion resistance of different materials such as gray cast irons, ductile irons, stainless steels, nonferrous metals and alloys such as aluminum and copper alloys [1721].

The present work includes analysis of the influence of mechanical alloying duration on the cavitation erosion resistance of copper matrix composites as well as the influence of different fabrication processes. Cavitation test was performed on hot-pressed samples obtained from powders after 5 and 30 hours of MA, and on laser-sintered samples obtained from powders after 30 hours of MA. The best results of cavitation testing for both processes were compared. Microscopic investigations support discussion of the results.

\section{Experimental work}

\section{Materials}

The powders used as starting materials were copper (99.5\% purity, average particle size $100 \mu \mathrm{m})$, zirconium $(99.5 \%$ purity, average particle size $1 \mu \mathrm{m})$ and boron $(97 \%$ purity, average particle size $0.08 \mu \mathrm{m})$. Starting powder mixture with compositions $\mathrm{Cu} 1.1 \mathrm{Zr}-0.3 \mathrm{~B}$ (wt.\%) and $\mathrm{Cu}-4.1 \mathrm{Zr}-1.1 \mathrm{~B}$ (wt.\%) were homogenized in Turbula Type 
2TC Mixer for 1 hour with stirring speed of $500 \mathrm{rpm}$. The homogenized powder mixture was mechanically alloyed in Netzsch attritor mill for 5 and 30 hours with stirring speed of $330 \mathrm{rpm}$. Mechanical alloying was performed in argon atmosphere using stainless steel balls ( $6 \mathrm{~mm}$ in diameter), and ball-to-powder weight ratio was 5:1.

Preparation of hot-pressed and laser-sintered copper matrix composites

Hot pressing of mechanically alloyed mixtures $(\mathrm{Cu} 1.1 \mathrm{Zr}-0.3 \mathrm{~B}$ (wt.\%) and $\mathrm{Cu}-$ $4.1 \mathrm{Zr}-1.1 \mathrm{~B}(\mathrm{wt} . \%)$ ) was carried out in Astro furnace with graphite mold (10 mm diameter). The heating rate was $15^{\circ} \mathrm{C} / \mathrm{min}$, at a temperature of $950{ }^{\circ} \mathrm{C}$ and under a pressure of $35 \mathrm{MPa}$. Retention time was 2.5 hours. Obtained compacts were $5 \mathrm{~mm}$ in height. For laser-sintering method, mechanically alloyed powders $(\mathrm{Cu}-4.1 \mathrm{Zr}-1.1 \mathrm{~B}(\mathrm{wt} \%)$, and after 30 hours of MA) were cold pressed by the applied pressure of $180 \mathrm{MPa}$, to produce green compacts. Laser-sintering of green compacts was carried out with Nd: YAG pulsed laser radiation in the nitrogen atmosphere. Samples were distinguished by a number of scans from 1 up to 4. Except for the number of scans, parameters of laser sintering for all samples were the same: frequency $3 \mathrm{~Hz}$, pulse duration $10 \mathrm{~ms}$ (for the sample with 4 scans $8 \mathrm{~ms}$ ), pulse energy $22 \mathrm{~J}$ (for the sample with 4 scans $18.5 \mathrm{~ms}$ ). Obtained laser-sintered samples were $300 \mu \mathrm{m}$ in height. Properties of obtained copper matrix composites are given in Table 1. As was reported in previous studies [6-8] in situ forming of $\mathrm{ZrB}_{2}$ particles was achieved during hot-pressing and laser-sintering process. The density of the samples was determined by Archimedes method, and the rule of mixture determined theoretical density.

Table 1. Properties of hot-pressed and laser-sintered copper matrix composite with corresponding abbreviations.

\begin{tabular}{|c|c|c|c|c|c|}
\hline Sample & & Process & $\begin{array}{l}\text { Porosity, } \\
\%\end{array}$ & $\begin{array}{l}\text { Vickers } \\
\text { Hardness } * *\end{array}$ & $\begin{array}{l}\text { Abbreviation } \\
\mathrm{s}\end{array}$ \\
\hline \multirow{5}{*}{$\begin{array}{l}\text { Mechanical } \\
\text { alloying time / } \\
\text { amount of } \mathrm{ZrB}_{2} \\
\text { particles }\end{array}$} & Pure copper & \multirow{5}{*}{ hot-pressing } & 0.01 & $60 \pm 0.4$ & $\mathrm{CuHP}$ \\
\hline & 5 h / low (L) & & 5.38 & $81 \pm 4$ & 5hHP-L \\
\hline & 30 h / low (L) & & 3.12 & $89 \pm 3$ & 30hHP-L \\
\hline & 5 h / high $(\mathrm{H})$ & & 6.56 & $101 \pm 3$ & 5hHP-H \\
\hline & 30 h / high $(\mathrm{H})$ & & 4.06 & $155 \pm 2$ & 30hHP-H \\
\hline \multirow{3}{*}{$\begin{array}{l}\text { Number of } \\
\text { scans }\end{array}$} & 2 & \multirow{3}{*}{ laser-sintering } & 8.31 & $140 \pm 16$ & $\operatorname{LS} 2 \mathrm{x}$ \\
\hline & 3 & & 2.47 & $165 \pm 12$ & LS3x \\
\hline & 4 & & 2.16 & $180 \pm 7$ & LS4x \\
\hline
\end{tabular}

* Low (L) and high $(\mathrm{H})$ amount of $\mathrm{ZrB}_{2}$ particles indicates volume fraction of $1 \%$ and $7 \%$, respectively. ** For laser-sintering Vickers hardness was measured as HV0.01 and for hotpressing as HV1. For both measurements dwelling time was $15 \mathrm{~s}$.

\section{Cavitation test}


The ultrasonic vibratory cavitation test set up (stationary sample method according to the ASTM G32 standard) was used for cavitation erosion analysis [22]. The frequency of vibration and peak-to-peak displacement amplitude of the horn were $20 \mathrm{kHz}$ and $50 \mu \mathrm{m}$, respectively, with separation of $0.5 \mathrm{~mm}$ between the sample and the horn tip. The test liquid was water maintained at $25^{\circ} \mathrm{C}$ [22-25]. The mass loss measurements were performed after each exposure to the cavitation (every $10 \mathrm{~min}$ ) for a test period of 120 min for HP compacts and laser-sintered samples every $10 \mathrm{~min}$ for a test period of $60 \mathrm{~min}$. Differences in cavitation test duration are due to a thickness of the sample. Before and after each test interval the samples were cleaned and dried with hot air. Mass losses of the tested samples were measured using an analytical balance with an accuracy of \pm 0.1 $\mathrm{mg}$. Cavitation erosion rate was calculated as a slope of the line obtained after a linear fit of mass loss vs. exposure time curve.

\section{Microscopic examination}

The microstructure of samples before and after cavitation test was investigated by JEOL-JSM 5800LV scanning electron microscope (SEM) at an accelerating voltage of $20 \mathrm{kV}$. Detailed analysis of microstructure before cavitation test was reported in our previous studies [6-8].

\section{Results and discussion}

Size and distribution of reinforcements in copper matrix depend on their percentage and mechanical alloying duration or number of scans in case of laser-sintering and show a strong influence on mechanical properties $[8,26]$. The highest densities and hardness have samples obtained by hot-pressing from powders mechanically alloyed for $30 \mathrm{~h}$ or by 4 scans during laser-sintering. Compared to pure copper sample, the full densification of the $\mathrm{Cu}-\mathrm{ZrB}_{2}$ alloy was not achieved because of hardening effects due to the presence of $\mathrm{ZrB}_{2}$ particles and agglomerates with varying sizes [6]. Therefore, it was noticed that longer milling time provides more homogeneous distribution of reinforcing particles and better densification which have a substantial influence on the hardness of this composite. In previous studies [7, 8] amount of present reinforcements in the copper matrix was determined as $1 \% \mathrm{ZrB}_{2}$ for system $\mathrm{Cu}-1.1$ wt. $\% \mathrm{Zr}-0.3$ wt. \% B; $7 \% \mathrm{ZrB}_{2}$ for system $\mathrm{Cu}-4.1 \mathrm{wt} . \% \mathrm{Zr}-1.1 \mathrm{wt} . \% \mathrm{~B}$ after hot-pressing; around 3.5\% for lasersintered samples of a green compact with $\mathrm{Cu}-4.1 \mathrm{wt} . \% \mathrm{Zr}-1.1 \mathrm{wt} . \% \mathrm{~B}$ composition. As was reported $[6,7]$, the presence of higher amount of submicron reinforcing particles in the copper matrix was observed after $30 \mathrm{~h}$ of MA comparing to $5 \mathrm{~h}$, which leads to higher hardness. In Fig. 1. results of cavitation erosion testing of hot-pressed (Fig.1a) and lasersintered (Fig.1b) samples are shown. Hot-pressed samples with the same duration of mechanical alloying show similar cavitation resistance despite the various amount of present reinforcements. However, observing the overall behavior of hot-pressed samples, the influence of reinforcement amount on cavitation resistance can be noticed, especially after $30 \mathrm{~min}$ of cavitation erosion test. Sample 30hHP-H which shows the highest cavitation erosion resistance also shows the highest mass loss at the beginning of cavitation test, but after 30 min the mass loss rate decreases, i.e., steady-state rate occurs due to surface roughness. The behavior of laser-sintered samples during cavitation erosion test depends on the number of scans. According to the density and hardness values of the laser-sintered samples, it was expected that LS4x shows the highest cavitation erosion resistance and LS2x the lowest. 

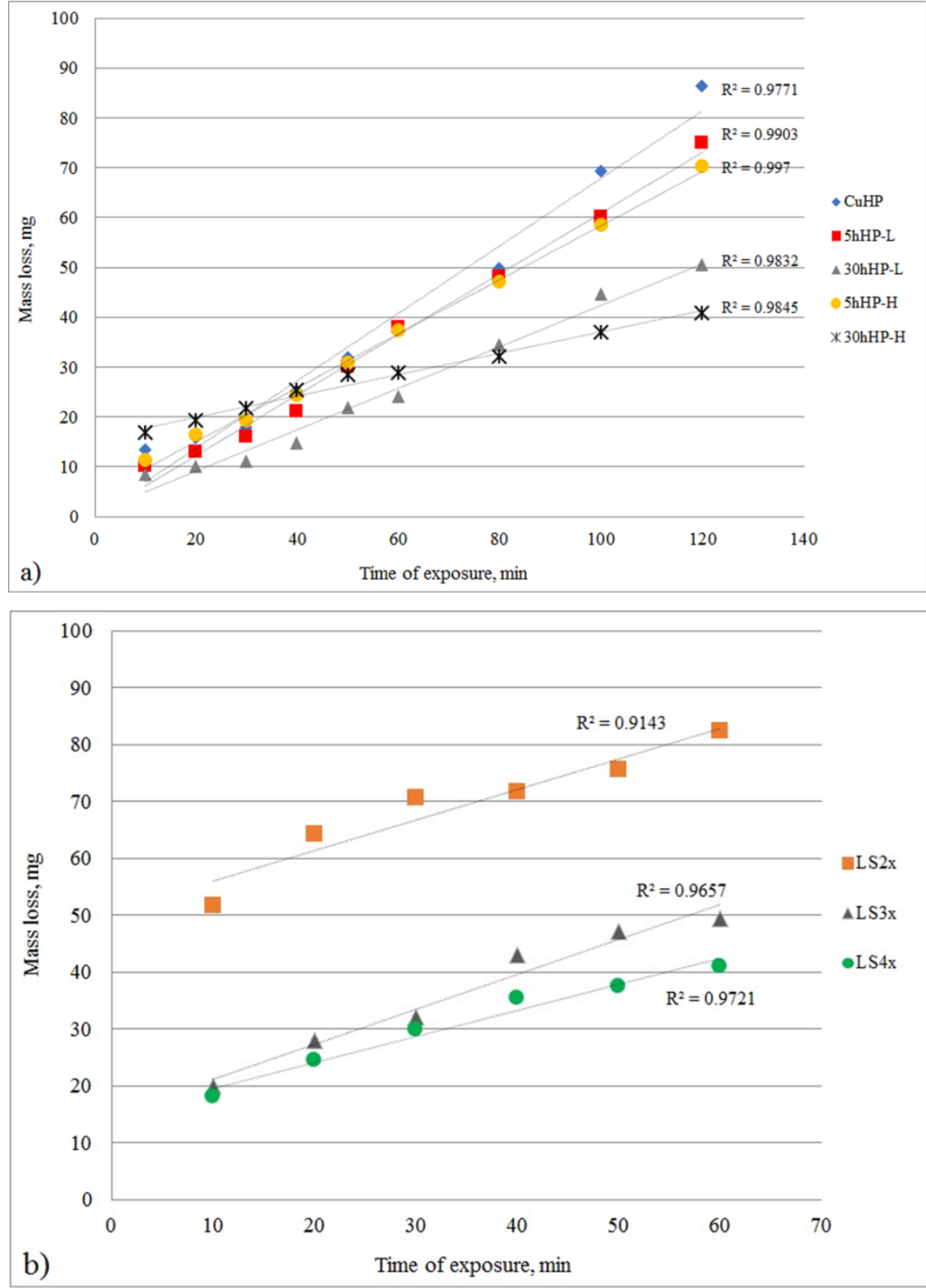

Fig. 1. Mass loss during cavitation erosion testing of a) hot-pressed and b) lasersintered samples.

All samples do not show any incubation period during cavitation erosion testing, probably due to the presence of agglomerates or coarse $\mathrm{ZrB}_{2}$ particles which provide increasing of some local peeling of the copper matrix. Also, $\mathrm{ZrB}_{2}$ particles can sustain higher loads compared to the copper matrix because of their higher hardness and 
consequently local strain of the copper matrix is higher. On the other hand, the presence of reinforcements in copper matrix increases the dislocation density and decreases the grain size since the reinforcing particles act as sites of nucleation during solidification. The grain size decreases due to the formation of subgrains with a high dislocation density. Also, it is supposed that in this composite material the subgrains are formed and surrounded by $\mathrm{ZrB}_{2}$ particles which can act as barriers to the dislocations movement. As can be noticed, samples 30hHP-H and with LS4x show the best results in performed cavitation erosion testing which confirms the correlation between cavitation resistance and mechanical and microstructural parameters. Therefore, comparing these two samples, it can be concluded that laser-sintering technique provides samples with slightly better cavitation erosion resistance than hot-pressed samples. This fact is supported by similar values of cavitation erosion rate after $60 \mathrm{~min}$ of exposure $(0.32 \mathrm{mg} / \mathrm{min}$ for $30 \mathrm{hHP}-\mathrm{H}$ and $0.41 \mathrm{mg} / \mathrm{min}$ for LS4x) despite the significant difference in the sample thickness $(5 \mathrm{~mm}$ for 30hHP-H and $300 \mu \mathrm{m}$ for LS4x) as well as the difference in amount of $\mathrm{ZrB}_{2}$ particles (7\% in 30hHP-H and $3.5 \%$ in LS4x). Lower values of cavitation rates indicate higher cavitation erosion resistance (Fig. 2).

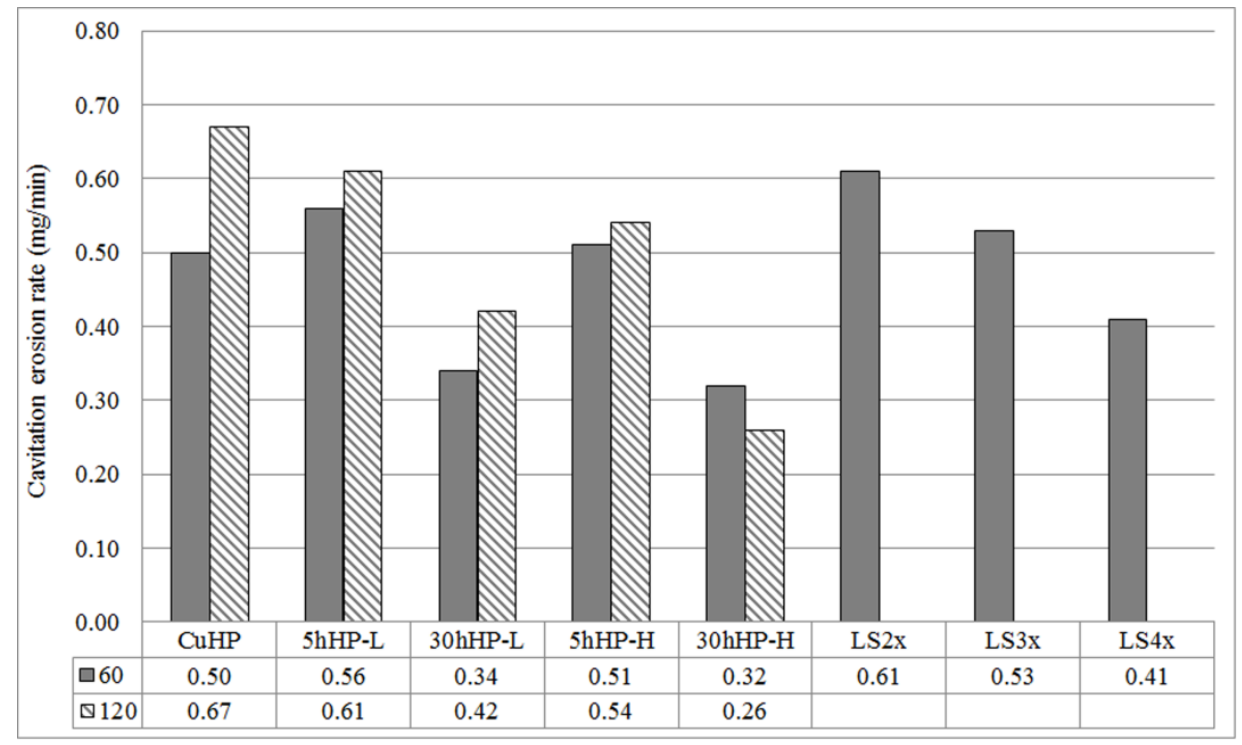

Fig. 2. Cavitation erosion rates of hot-pressed and laser-sintered samples.

The SEM investigation has shown evenly spread corrugated surface of the copper sample and randomly distributed pits in the corrugated surface of other samples. Since material response to cavitation erosion attack differs depending on the production technique, mechanisms of damage also vary. As was reported [21], the final surface damage caused by cavitation erosion is a consequence of two mechanisms: the individual collapse of bubbles and simultaneous collapses of the whole cloud of bubbles close to the solid surface. In ultrasonic vibratory cavitation erosion test set these mechanisms can occur individually or jointly. The progress of cavitation erosion on the surface of hotpressed samples observed by SEM is shown in Fig. 3. Damaged surfaces of CuHP, 5hHP$\mathrm{L}$, and $30 \mathrm{hHP}-\mathrm{H}$ after $120 \mathrm{~min}$ of cavitation erosion test are shown in Fig. 3a-c, 
respectively. These SEM micrographs show mainly corrugated surface. Since copper is a ductile material with a low hardness, it shows a high material loss. It is assumed that the dominant mechanism is a simultaneous collapse of the whole cloud of bubbles. On the other hand, sample (30hHP-H) with the lowest material loss shows the lesser number of shallow pits probably due to the occurrence of mixed ductile/brittle-mode cracks caused by the presence of $\mathrm{ZrB}_{2}$ particles, which indicates that individual collapse of bubbles is the more dominant mechanism. Eroded surface of CuHP sample shows plastically deformed grains due to the presence of cleavage as dominant fracture mode, but the ductile fracture was also noted (Fig. 3a). Addition of $\mathrm{ZrB}_{2}$ particles induces mixed fracture (Fig. 3b,c), both ductile and brittle mode cracks occurred, and cavitation attack is primarily on grain boundaries (a few mentioned cracks occurred on the grain boundary were marked with arrows). The corrugated surface is observed in all samples, and distribution and depth of pits are in correlation with the distribution of reinforcing particles. Hot-pressed samples show grain boundary erosion and distribution of pits inside the grains depends on amount and distribution of $\mathrm{ZrB}_{2}$ particles as well as grain size. Observing the surface of 30hHP-H sample shown in Fig. 3c, it can be noticed the presence of non-damaged areas (marked with arrows) as a consequence of relatively high hardness due to the presence of submicron $\mathrm{ZrB}_{2}$ particles and probably small grains.

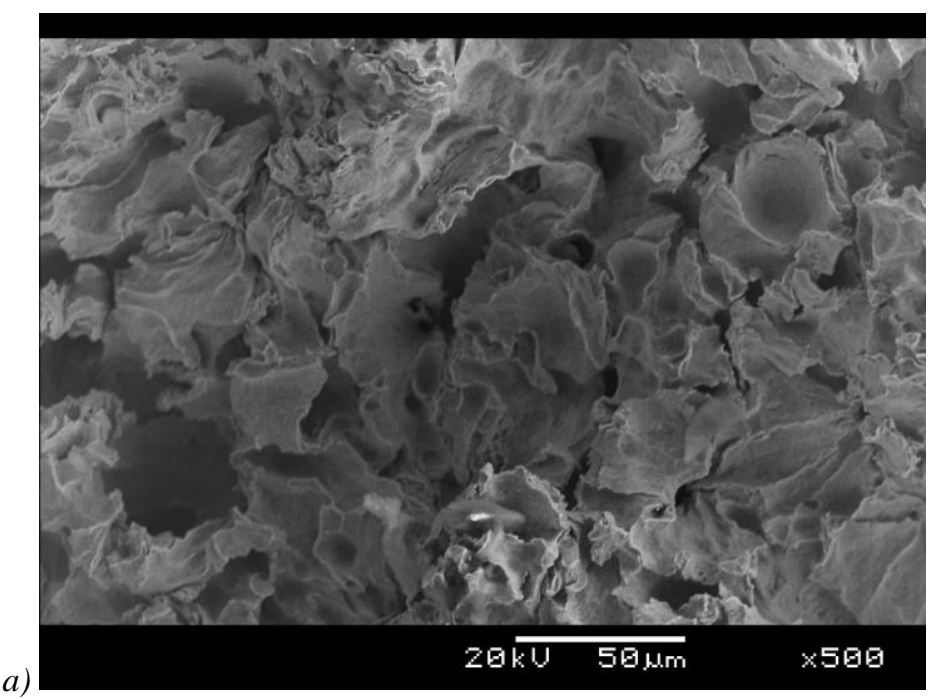


$b$
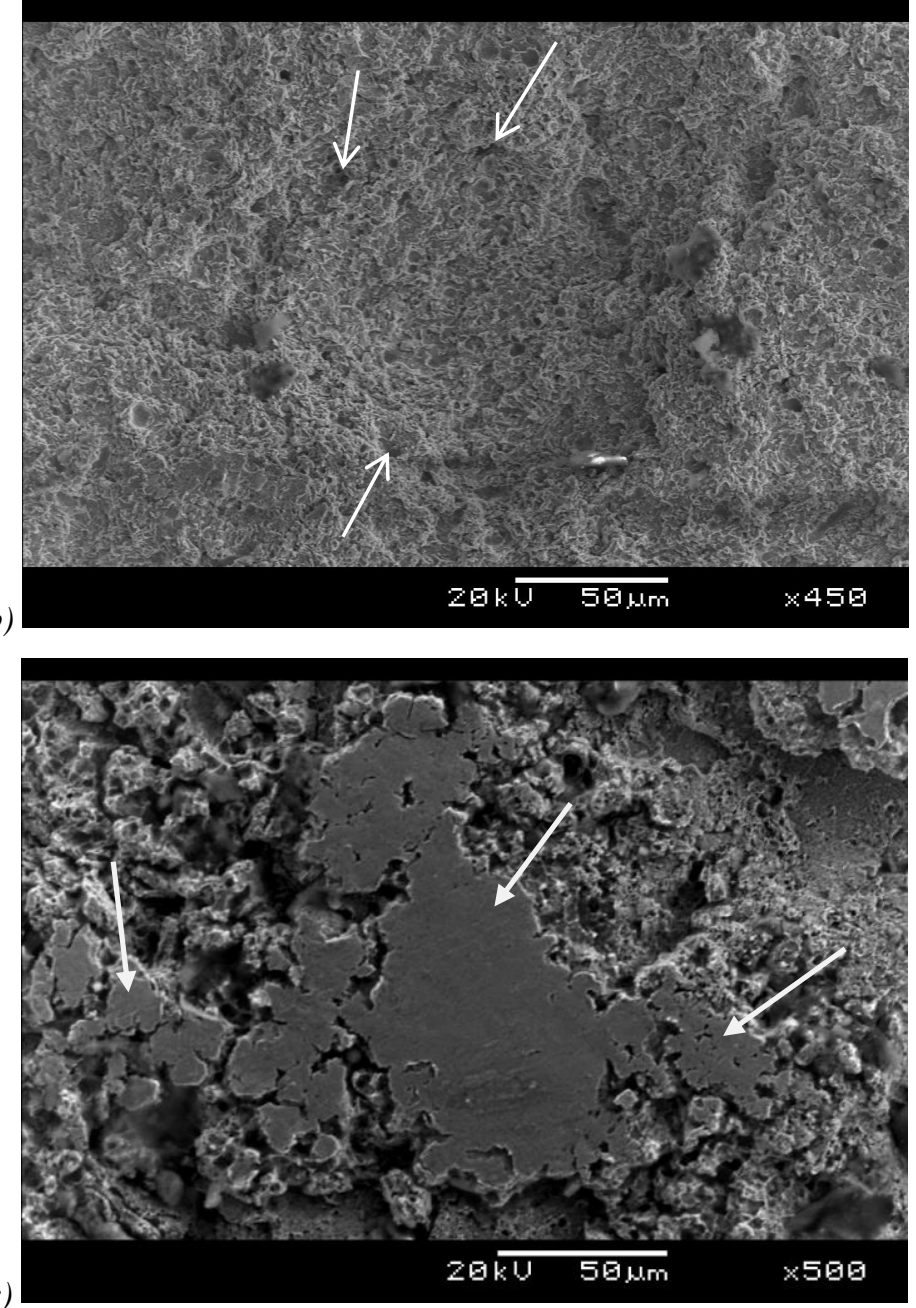

Fig. 3. SEM micrographs of the damaged surface of hot-pressed samples: a) CuHP,

b) $5 \mathrm{hHP}-\mathrm{L}$, and c) $30 \mathrm{hHP}-\mathrm{H}$, after 120 min of cavitation erosion testing.

Laser-sintered samples show similar behavior which is presented in Fig. 4. Sample LS2x (Fig. 4a) shows high material loss between scanning lines after 60 min of cavitation erosion testing due to the presence of pores or unmelted areas. Sample LS3x (not shown in this paper) exhibits the similar behavior as LS2x, i.e., erosion along areas between scanning lines as the dominant damaged surface but with the lower material loss. Observing surface of LS4x sample (Fig. 4b) after 60 min only a few pits were noticed surrounded mainly by non-damaged areas. With increasing the number of scans, material porosity decreases (as well as unmelted regions) and cavitation resistance increases. Also, the presence of $\mathrm{ZrB}_{2}$ increased the work-hardening rate and combined with all facts mentioned above enables the individual collapse of bubbles as a more dominant mechanism. 
a)
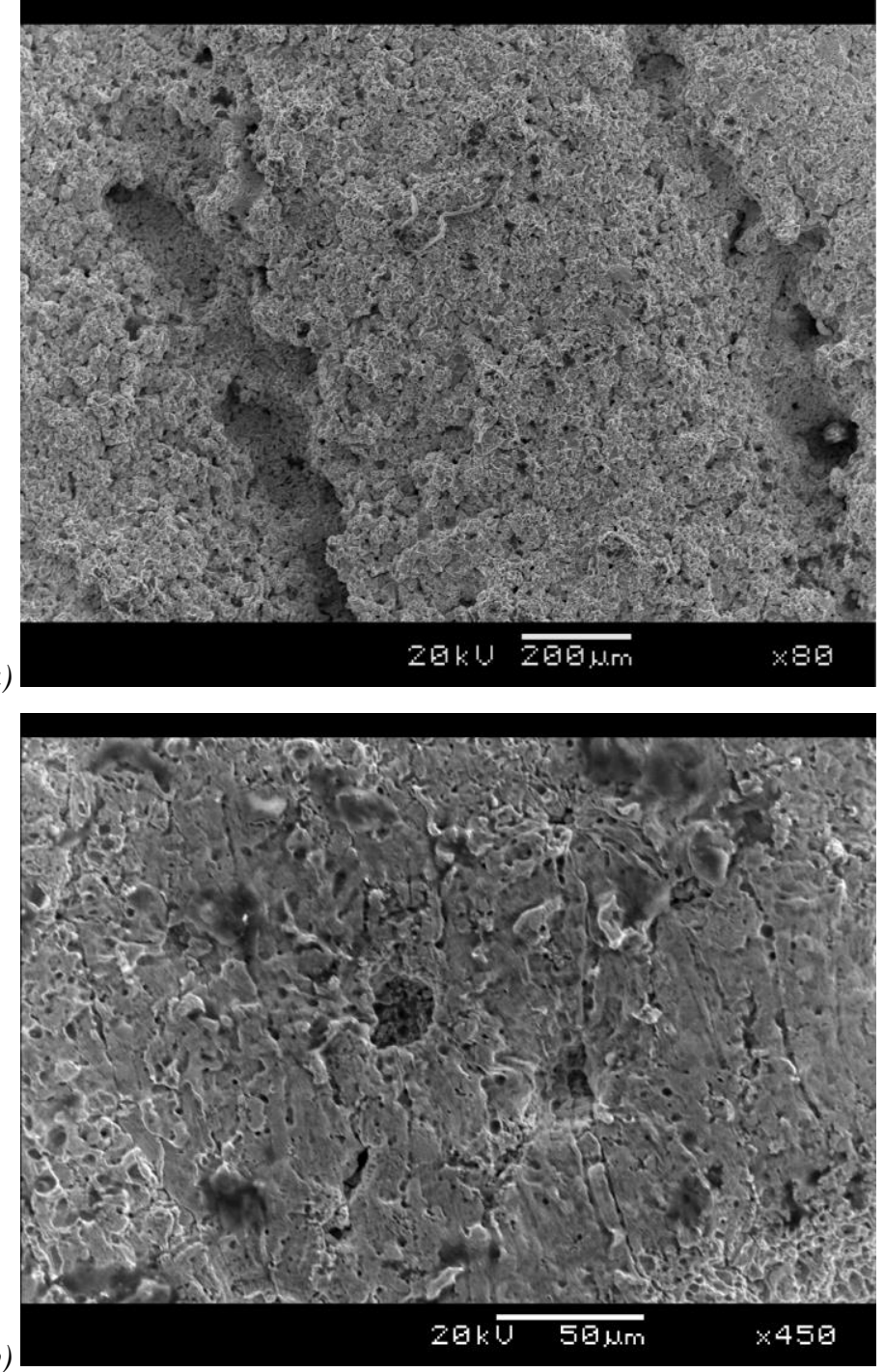

Fig. 4. SEM micrographs of the damaged surface of laser-sintered samples: a) LS2 $x$ and b) LS4x, after 60 min of cavitation erosion testing.

It may be concluded that cavitation erosion resistance depends on mechanical alloying duration, as well as production process. Overall, as was expected, samples with higher hardness show better cavitation erosion resistance. 


\section{Conclusion}

In this paper mass loss was used as a measure of cavitation erosion resistance of copper matrix composites. By adding the reinforcing $\mathrm{ZrB}_{2}$ particles in the copper matrix, cavitation erosion resistance of the matrix improves. In the first $30 \mathrm{~min}$ mass loss has almost identical trend for samples with the same amount of $\mathrm{ZrB}_{2}$ particles, and after 30 min greater influence on the trend of mass loss vs. time curve shows mechanical alloying duration. Also, laser-sintered samples show slightly better cavitation erosion resistance compared to hot-pressed samples (taking into account the significant difference in the sample thickness), and it can be concluded that production techniques influence cavitation erosion resistance. On the other hand, duration of mechanical alloying, distribution and size of $\mathrm{ZrB}_{2}$ particles in the copper matrix increase its ability to work-hardening and absorption of cavitation energy. The lowest cavitation erosion resistance of $\mathrm{Cu}-\mathrm{ZrB}{ }_{2}$ composites shows laser-sintered sample after 2 scans due to high porosity and unmelted regions. With increasing the number of scans, the cavitation resistance also increases.

\section{Acknowledgment}

The Ministry of Education has financed the most of the research presented in this paper, science and technological development of Serbia as part of Projects: OI 172005, TR 35002 and III 45012. The authors declare that there is no conflict of interest regarding the publication of this paper.

\section{References}

[1] H. Kimura, N. Muramatsu, K. Suzuki, Copper alloy and copper alloy manufacturing method, U.S. Patent Application 11/084,692, filed March 18, 2005.

[2] K. U. Kainer, Metal Matrix Composites, Weinheim: Wiley-VCH VerlagGmbH\&Co. $\mathrm{KGaA}, 2006$.

[3] R. Konecna, S. Fintova, Copper and Copper Alloys: Casting, Classification and Characteristic Microstructures, Zilina, 2012.

[4] M. Li, S.J. Zinkle: Compr Nucl Mater, 4 (2012) 667-690.

[5] J.S. Andrus, R.G. Gordon, Contractor Report no.NAS3-23858, NASA, Florida, 1989.

[6] J. Ruzic, J. Stasic, S. Marković, K. Raic, D. Bozic: Sci Sinter, 46 (2014) 217-224.

[7] J. Ruzic, J. Stasic, V. Rajkovic, K. Raic, D. Bozic: Sci Eng Compos Mater, 22 (2015) 665-671.

[8] J. Stasic, M. Trtica, V. Rajkovic, J. Ruzic, D. Bozic: Applied Surface Science, 321 (2014) 353-357.

[9] R.T. Knapp, J.W. Daily, F.G. Hammit, Cavitation, McGraw-Hill, New York, 1970.

[10] S. Suslick, A. Cruma, Handbook of acoustics, Wiley, New York, 1994.

[11] C.E. Brennen, Cavitation and bubble dynamics, Oxford University Press, 1995.

[12]F.G. Hammit, Cavitation and Multiphase Flow Phenomena, McGraw-Hill Inc., 1980.

[13] Y. K. Zhou, F.G. Hammit: Wear, 86 (1983) 299-313.

[14] C.J. Heathcock, B.E. Protheroe, A. Ball: Wear, 81 (1982) 311-327.

[15]E.H.R. Wade, C.M. Preece: Metall Trans A, 9 (1978) 1299-1309.

[16] A. Thiruvengadam: J Basic Eng, 3 (1963) 365-376.

[17] T. Okada, Y. Iwai, A. Yamamoto: Wear, 84 (1983) 297-312.

[18] S. Hattori, R. Ishikura: Wear, 268 (2010) 109-116. 
[19] G. Bregliozzi, A.D. Schino, S.I.U. Ahmed, J.M. Kenny, H. Haefke: Wear, 258 (2005) 503-510.

[20] S. Hattori, T. Kitagawa: Wear, 269 (2010) 443-448.

[21] J. Hucinska, M. Glowacka: Metall Trans A, 32A (2001) 1325-1333.

[22] ASTM G32-92, Standard Method of Vibratory Cavitation Erosion Test, Philadelphia, 1992.

[23] M. Dojcinovic, S. Markovic: J Serb Chem Soc, 71 (2006) 977-984.

[24] M. Dojcinovic, T. Volkov-Husovic: Mater Lett, 62 (2008) 953-956.

[25] M. Dojcinovic: Hem Ind, 67 (2013) 323-330.

(C) (i) Creative Commons License

This work is licensed under a Creative Commons Attribution 4.0 International License. 